\title{
Awareness Among Dentists Regarding Ergonomics in Dental Practice: A Cross-sectional Survey
}

\author{
${ }^{1}$ Harish C Jadhav, ${ }^{2}$ Prashanth Y Vishwakarma, ${ }^{3}$ Arun S Dodamani, ${ }^{4}$ Minal M Kshirsagar, ${ }^{5}$ Girija A Dodamani, ${ }^{6}$ Rahul G Naik
}

\begin{abstract}
Background: Dentistry is a highly skilled profession, requires high concentration within a confined working environment, which requires different postural variations. Ergonomics is an applied science concerned with designing products and procedures for maximum efficiency and safety in dental practice.
\end{abstract}

Aim: To assess the awareness of dentists towards ergonomics.

Materials and methods: The present study was conducted among dentists of Dhule city which is cross-sectional, Maharashtra, India. A structured, self-administered questionnaire consisting of 19 closed-ended and one opened ended questions was administered to 135 dentists out of whom 109 responded. Out of 109 dentists, 33 were MDS. Thirty-eight were BDS and 38 were postgraduate students (PG). PG students were selected from the dental institute. The collected data were tabulated and subjected to analysis using appropriate statistical tests.

Result: Though there was statistically no significant difference regarding awareness of ergonomics in between MDS, BDS and PG students, it was seen that there was awareness present among dentists, but its incorporation in their practice was lacking. Several disorders like musculoskeletal disorders have been seen till date because of improper ergonomics.

Conclusion: Present study concludes that the majority of the dentists were having the knowledge and positive attitude towards ergonomics, but there was a lack of positive behavior towards it. It's a need of the hour to implement ergonomics strongly in the day to day life. Spreading awareness regarding ergonomics is necessary.

Keywords: Dentist, Ergonomics, Musculoskeletal diseases, Occupational hazards.

\footnotetext{
${ }^{1,5,6}$ Senior Lecturer, ${ }^{2}$ Reader, ${ }^{3}$ Principal, Professor and Head,

${ }^{4}$ Asssistant Professor

1-3,6 Department of Public Health Dentistry, ACPM Dental College, Dhule, Maharashtra, India

${ }^{4}$ Department of Public Health Dentistry, Government Dental College, Aurangabad, Dhule, Maharashtra, India
}

${ }^{5}$ Department of Prosthodontics, ACPM Dental College, Dhule, Maharashtra, India

Corresponding Author: Harish C Jadhav, Senior Lecturer, Department of Public Health Dentistry, ACPM Dental College, Dhule, Maharashtra, India, Phone: +919881248105, e-mail: drharishjadhav2003@gmail.com
How to cite this article: Jadhav HC, Vishwakarma PY, Dodamani AS, Kshirsagar MM, Dodamani GA, Naik RG. Awareness Among Dentists Regarding Ergonomics in Dental Practice: A Crosssectional Survey. J Oral Health Comm Dent 2018;12(3):85-89.

\section{Source of support: Nil}

Conflict of interest: None

\section{INTRODUCTION}

It was seen that dental professionals are commonly exposed to a variety of occupational hazards such as chemical, biological, ergonomic, etc. which sometimes create musculoskeletal disorders (MSDs). Dentist often has to limit their professional activities due to MSDs which may affect their quality of life negatively. Successful dental practice requires a healthy dentist. Despite the fact that though $88 \%$ of dentist report good or excellent health, ${ }^{1}$ some studies till now have shown that one out of 10 dentists are suffering from poor general health and three out of 10 dentists are suffering from the poor physical state. ${ }^{2}$

Nowadays musculoskeletal health of dental professionals is the subject of numerous research work, and they are focusing more on the pain experienced by them. Previous literature have shown that back, neck, and shoulder or arm pain is present in up to $81 \%$ of dental operators. ${ }^{3}$ Back pain is one of the most common complain followed by neck and shoulder pain. If this pain or discomfort is ignored consistently, this may lead to an irreversible injury. ${ }^{4}$ Sometimes dental professionals maintain their position for prolonged periods which results in severe pain. ${ }^{5}$

Ergonomics is the science that fits the job to a person's anatomical, physiological and psychological characteristics in such a way that it enhances human efficiency and well-being. The goal of ergonomics is to stabilize a safe, healthy, and comfortable working environment, to prevent health problems and improvisation of work. Dentistry is a highly skilled profession where skills are confined oral cavity and mouth, and it requires repeated, application of precise force while delivering oral health services. ${ }^{6}$

There is no uniform medical information and or sufficient understanding of the nature of MSDs. Significant difficulties in diagnosis generate an on-going debate on many aspects of these conditions. ${ }^{7}$ Such problems can be avoided by spreading awareness of postures during different dental procedures, redesigning the workplace 
ergonomically, examining the impact of instrument use on pain in extremities and following healthy work practices to reduce the stress of dental workload on the practitioners. ${ }^{8}$ If ergonomics principles are applied to the field of dentistry, it will help in lowering cognitive and physical stress level, prevention of occupation-related disorders, thus, helping in the improvisation of productivity of a person and it will provide more comfort to the dentist and patient also. ${ }^{6}$

So an attempt was made through the present study to assess the awareness of dentists regarding ergonomics in dental practice.

\section{MATERIALS AND METHODS}

The present study was a cross-sectional study conducted among dentists.

\section{Obtaining Ethical Clearance and Consent}

Prior to the start of the study, a protocol of the intended study was submitted to the Ethical Review Committee, of Dental Institute and ethical clearance for the present study was obtained. Purpose of the present study was told to every participant and written informed consent was taken from each participant.

\section{Sampling Technique}

In the present study is based on a convenience sampling technique was used where participants were selected based on their convenient accessibility and proximity to the researcher.

\section{Preparation of Questionnaire}

A structured and self-administered questionnaire consisting of 19 closed-ended and one open-ended questions was prepared and tested by a pilot study. The questionnaire was given to subject matter experts. The required changes were made, and the questionnaire was finalized.

The list of dentists was obtained from Indian Dental Association (IDA). The questionnaire was distributed among 135 dentists (90 dentists and 45 PG students from the dental institute), out of which 109 returned back completed questionnaire (response rate $80.7 \%$ ) In the present study 33 MDS, 38 BDS and 38 PG students participated voluntarily. The information regarding age, gender, profession (specialty branch) was collected to assess the awareness of dentists regarding ergonomics in dental practice.

\section{Duration}

The present study was conducted throughout one week.

\section{Administration of the Questionnaire}

The questionnaire was administered to dentists in printed form, and they were given enough time to complete it.

\section{Inclusion Criteria}

- Participants those who were willing to participate.

- Participants who filled the entire questionnaire.

- Exclusion criteria:

- Participants those who were not able to give time.

- Participants those who were not available during the period of the present study.

\section{Statistical Analysis}

The collected data were tabulated in Microsoft Excel sheet and subjected to statistical analysis using appropriate statistical tests. Statistical Package for Social Sciences (SPSS-version 16).

\section{RESULTS}

When the duration of physical exercise was asked it was seen that 15 minutes of physical exercise was highest reported by PG students (100\%) followed by MDS (84.8\%) and BDS (47.4\%) dentists. 15 to 30 minutes of physical exercise was reported highest by BDS (28.9\%) followed by MDS (9.1\%) and PG students (0). 30 minutes to 1 hour physical exercise was highest reported by BDS (23.7\%) followed by MDS (6.1\%) and PG students (0). It showed a statistically significant difference. When the relation of physical activity with body pain was asked 88 participants were agreed on it (Table 1B). When they were asked about the association of body pain and exercise in between appointments, 43 participants were agreed on it. Association of body pain and practice (in terms of years) was highest reported by PG students followed by BDS and MDS (Tables $1 \mathrm{~A}$ to $1 \mathrm{D})$.

Table 1A: Duration of physical exercise (\%) Chi-square test

\begin{tabular}{lllll}
\hline & \multicolumn{4}{c}{ Duration of physical exercise } \\
\cline { 2 - 5 } Group & 15 mins & $15-30$ mins & 30 mins $-1 \mathrm{hr}$ & 0 \\
\hline PG & $100 \%$ & 0 & 0 & 0.001 \\
MDS & $84.8 \%$ & $9.1 \%$ & $6.1 \%$ & \\
BDS & $47.4 \%$ & $28.9 \%$ & $23.7 \%$ & \\
\hline
\end{tabular}


Awareness Among Dentists Regarding Ergonomics in Dental Practice: A Cross-sectional Survey

Table 1B: Relation of physical activity with body pain Mann-Whitney test

\begin{tabular}{lllll}
\hline Physical activity & Body pain & $N$ & Mean rank & $p$-value \\
\hline & Yes & 88 & 53.80 & 0.270 \\
& No & 21 & 60.02 & \\
\hline
\end{tabular}

Table 1C: Association between body pain and in between appointment exercise

\begin{tabular}{llll}
\hline & \multicolumn{2}{c}{ Exercise in between two successive appointments } & N-value \\
\cline { 2 - 3 } Body Pain & Yes & No & 0.014 \\
\hline 43 & 45 & 014 \\
\hline
\end{tabular}

Table 1D: Association between body pain and no of years of practice Mann-Whitney test

\begin{tabular}{lllll}
\hline Group & Body pain & $N$ & Mean rank & p-value \\
\hline \multirow{2}{*}{ PG } & Yes & 34 & 19.50 & 0.950 \\
& No & 4 & 19.50 & 0.158 \\
\multirow{2}{*}{ MDS } & Yes & 26 & 15.83 & 0.045 \\
\hline \multirow{2}{*}{ BDS } & No & 7 & 21.36 & 21.52 \\
\end{tabular}

Awareness regarding musculoskeletal disorders (MSDs) when assessed in between three groups it was seen that MDS were aware highest (94\%) followed by PG students (79\%) and BDS (76\%) (Table 2).

Self-reported risk factors for MSDs when they were asked it was seen that, vibration of hand instrument was reported highest by PG students (87\%) followed by MDS (70\%) and BDS (66\%) (Table 3).

It was seen from the present study that $92 \%$ of PG students were aware about OSHA (Occupational Safety and Health Administration) followed by MDS (82\%) and BDS (66\%). It showed a statistically significant difference (Table 4).

Group-wise distribution of pain in body region showed that it was highest reported in back region by

Table 2: Awareness regarding MSDs among three groups

\begin{tabular}{lllll}
\hline Group & Awareness & $N$ & Percent & p-value \\
\cline { 1 - 3 } PG & Yes & 30 & 78.9 & \\
& No & 8 & 21.1 & \\
\cline { 1 - 3 } MDS & Yes & 31 & 93.9 & \multirow{2}{*}{0.114} \\
\cline { 1 - 3 } BDS & No & 2 & 6.1 & \\
& Yes & 29 & 76.3 & \\
\hline
\end{tabular}

Table 4: Awareness about OSHA Chi-square Test

\begin{tabular}{|c|c|c|c|c|}
\hline Group & Awareness & $N$ & Percent & $p$-value \\
\hline \multirow{2}{*}{$P G$} & Yes & 35 & 92.1 & \multirow{6}{*}{0.059} \\
\hline & No & 3 & 7.9 & \\
\hline \multirow{2}{*}{ MDS } & Yes & 27 & 81.8 & \\
\hline & No & 6 & 18.2 & \\
\hline \multirow{2}{*}{ BDS } & Yes & 25 & 65.8 & \\
\hline & No & 13 & 34.2 & \\
\hline
\end{tabular}

PG students (47\%) followed by BDS (42\%) and MDS (36\%). (Table 5)

Prevalence of muscle fatigue was highest reported by PG students (90\%) followed by MDS (79\%) and BDS (74\%). Prevalence of pain while using vibratory instruments was highest reported by MDS (42\%) followed by PG students (40\%) and BDS (37\%) (Table 6).

Factors reported to avoid MSDs (maintain an erect posture, avoid excessive finger/wrist moment, and work close to your body) were highest reported by PG students (29\%) followed by MDS (24\%) and BDS (23\%). (Table 7 )

\section{DISCUSSION}

Dentistry is a skilled profession which requires a lot of concentration and focus on micro and macro level details

Table 3: Self-reported risk factors for MSDs

\begin{tabular}{lllll}
\hline $\begin{array}{l}\text { Self-reported risk } \\
\text { factors }\end{array}$ & $P G$ & MDS & BDS & $p$-value \\
\hline $\begin{array}{l}\text { Vibration of hand } \\
\text { instruments }\end{array}$ & $86.8 \%$ & $69.7 \%$ & $65.8 \%$ & \\
Prolong static posture & $44.7 \%$ & $21.2 \%$ & $50 \%$ & \\
Position of patient & $2.6 \%$ & $3 \%$ & $7.9 \%$ & 0.114 \\
Position of dentist & $13.2 \%$ & $9.1 \%$ & $26.3 \%$ & \\
Workplace design & $0 \%$ & $3 \%$ & $0 \%$ & \\
\hline
\end{tabular}

Table 5: Group-wise distribution of body region pain (in percent)

\begin{tabular}{lllll}
\hline Region & $P G$ & MDS & BDS & $p$-value \\
\hline Neck & $10.5 \%$ & $15.2 \%$ & $13.2 \%$ & \\
Back & $47.4 \%$ & $36.4 \%$ & $42.1 \%$ & \\
Hand and wrist & $2.6 \%$ & $3 \%$ & $7.9 \%$ & 0.425 \\
$15.8 \%$ & $9.1 \%$ & $2.6 \%$ & $26.3 \%$ & \\
Shoulder & $0 \%$ & $3 \%$ & $0 \%$ & \\
All of the above & $26.3 \%$ & $36.4 \%$ & $42.1 \%$ & \\
\hline
\end{tabular}


Table 6: Prevalence of muscle fatigue

\begin{tabular}{lllll}
\hline Group & $P G$ & MDS & BDS & p-value \\
\hline $\begin{array}{l}\text { Prevalence of muscle } \\
\text { fatigue }\end{array}$ & $89.5 \%$ & $78.8 \%$ & $73.7 \%$ & 0.206 \\
$\begin{array}{l}\text { Prevalence of pain } \\
\text { while using vibratory } \\
\text { instruments }\end{array}$ & $39.5 \%$ & $42.4 \%$ & $36.8 \%$ & 0.891 \\
\hline
\end{tabular}

of the oral cavity during practice. Dental practitioners are more focused about patient's well-being; paying little or no attention to their working posture until they suffer pain or any discomfort. It is a high-risk profession for MSDs. Most dental professionals continuously complain of pain in some region in their professional life span. Dental professionals need to visualize the exact field of work and this adds a lot of strain on their muscles, as they need to be in the same position for a prolonged duration of time. Several repetitive small ranges of motions are involved in dental practice. ${ }^{9}$ Prevention of the occupational hazards is the primary objective of dental ergonomics.

Posture reflects the position of an individual which they maintain in space via his bone-muscle-skeletal system. Maintaining good postures helps the body to lower the energy expenditure, improves organ function and also helps to protect the individual against any occupational hazard. ${ }^{10}$ So the present study was conducted to assess the awareness of dentists regarding ergonomics.

From the present study, it was seen that most of the participants with less physical exercise suffered from pain. Few participants agreed that they do exercise in between appointments, and the number of years of practice is also related to the pain experience. (Tables $1 \mathrm{~A}$ to D) Prevalence of MSDs are increasing may be due to lack of understanding of ergonomic principles and uncomfortable working environment which was common in practice due to out-dated equipment. ${ }^{11}$

From the present study, it was seen that $79 \%$ of PG students, $94 \%$ MDS and $76 \%$ BDS were aware of ergonomics. (Table 2) This is contradictory with the study conducted by Madaan et al. where participants were a deficit in the knowledge of ergonomics while delivering dental care. ${ }^{12}$

Musculoskeletal pain sometimes may be induced due to mechanical vibrations affecting their body through the upper limbs and cause changes in vascular, neural, and osteoarticular systems. These changes may produce an occupational disease called vibration syndrome. ${ }^{13}$ The results of the present study showed that amongst selfreported risk factors, the pain was experienced while using vibratory instruments by $87 \%$ of the participants especially PG students (Table 3). This might be due to increased frequency of use of vibrating instrument owing to an increased workload. This is in accordance
Table 7: Factors reported to avoid MSDs

\begin{tabular}{llll}
\hline Groups & $P G$ & MDS & $B D S$ \\
\hline Maintain an erect posture & $8 \%$ & $9 \%$ & $12 \%$ \\
Avoid excessive finger/wrist & $1 \%$ & - & $2 \%$ \\
movements & & & \\
Work close to your body & - & - & $1 \%$ \\
All of the above & $29 \%$ & $24 \%$ & $23 \%$ \\
\hline
\end{tabular}

with the study conducted by Szymanska J where 67\% of students were experiencing pain after using vibratory instruments. ${ }^{13}$

From the present study, it was seen that $92 \%$ of PG students, $82 \%$ MDS and $66 \%$ BDS were aware of Occupational Safety and Health Administration (OSHA) which showed a statistically significant difference (Table 4).

Group-wise distribution of pain in the body region in the present study showed that most of the participants reported pain in the neck, back, wrist and hand and shoulder region, especially in the back region (Table 5). This might be due to the prolonged grips and uncomfortable postures throughout the day. ${ }^{14}$ Repetitive forceful pinching or gripping, nonneutral position, use of vibrating tools for longer duration are among the major risk factors for the development of musculoskeletal disorders of hand and wrists. ${ }^{15-18}$ Improper patient position, back position, and neutral position maintenance have been found to contribute to back pain. ${ }^{19,20}$

From the present study, it was seen that the prevalence of muscle fatigue was more reported in participants especially in PG students (Table 6). This might be due to uncomfortable postures as well as repetitive procedures, such as root canal treatment, dental restorations, cavity preparation, scaling or root planning, which may contribute greatly to MSDs and psychological stress both. Such postures may cause fatigue. ${ }^{6,11}$ This is in accordance with the study conducted by De Carvalho et al. in their study, 227 Brazilian dental students found an overall prevalence of Musculoskeletal pain during or after clinical work. Diaz-Caballero et al. in their study found an 80\% prevalence of musculoskeletal pain among dental students. ${ }^{18,19}$

When participants were asked about factors to avoid MSDs, most of them reported maintain an erect posture; avoid excessive finger/wrist movements (Table 7). This is in accordance with the study conducted by Kanteshwari et al. they found out that less than $50 \%$ of the participants indicated awareness regarding the ergonomic posture of which $70 \%$ had musculoskeletal pain. ${ }^{12}$ The main reason for the awkward postures can be a lack of awareness of the biomechanics of the body, contributing to the lack of knowledge about the impact of musculoskeletal disorders, the nature of work, little space to maneuver in relation to the mouth and posture in the state of a neutral, the exact nature of work and lack of knowledge about the issues of workplace ergonomic. ${ }^{20}$ 


\section{CONCLUSION}

Dentists frequently suffer from ill health effects or MSDs like back pain, neck pain or shoulder pain. From the present study it was seen that most of the participants were aware of ergonomics and MSDs, but while working in a confined area unknowingly, they tend to adjust their posture which leads to ill health effects. So it is necessary to create awareness and conduct the timely workshops related to principles of ergonomics to avoid ill health effects and long-term safety for efficient practice. Ergonomically designed dental instruments may help reduce the prevalence of MSDs. Four-handed dentistry is ergonomically an efficient way to provide good dental care, leading to an increase in efficiency and productivity of a person, reduction in stress level and fatigue, to increase safety in the dental treatments

\section{RECOMMENDATIONS}

The present study has its limitations. Its cross-sectional nature limited the present study. The severity of MSDs increases over the number of years of practice. The prevention and reduction of MSDs among dentists should always focus on their knowledge regarding dental ergonomics and spreading its awareness. An interdisciplinary approach is required to address the concern, and continuous efforts should be taken for the prevention of MSDs in dental professionals. This is a need of the hour to take continuous efforts to discover new prevention strategies.

\section{PUBLIC HEALTH SIGNIFICANCE}

It was seen from the present study that theoretical knowledge regarding ergonomics among students and dental professionals was more than its application in clinical work. The goal of ergonomics is to establish a healthy and comfortable working environment thereby improving working efficiency. There is a need for implementation of principles of ergonomics in the day to day life and dental curriculum; so that chances of young dental professionals to get musculoskeletal disorders will be reduced. Therefore, it is important to provide training regarding ergonomics and to conduct preventive programs. It will be useful to all dentists to acquire knowledge regarding ergonomics during their clinical practices.

\section{REFERENCES}

1. Kupcinskas L, Petrauskas D. Hepatitis-Mediku Profesine liga. Journal of Stomatologija. 2003;11(1):22.

2. Gorter RC, Eijkman MAJ, Hoogstraten J. Burnout and Health among Deutch Dentist. European Journal Oral Sciences 2000;108(4):261-267.
3. Bramson JB, Smith S, Romagnoli G. Evaluating Dental Office Ergonomic Risk Factors And Hazards. Journal of American Dental Association, 1998;129(2):174-183.

4. Wadhawan R, Luthra K, Sidhu JK, Solanki G. Comforting the dental surgeon- A review on Ergonomics. International Journal of Odontological Sciences 2015;1(1):1-9.

5. Kierklo A, Kobus A, Jaworska M, Botuliñski B. Work-related muculoskeletal disorders among dentists-a questionnaire survey. Annals of Agricultural and Environmental Medicine. 2011;18(1):79-84.

6. Sahu D, Tandon S, Dhingra S, Chinmaya BR, Prasad S, Bali E, et al. Prevalence of musculoskeletal disorders among dentists: A pilot cross-sectional survey. J Indian Assoc Public Health Dent [serial online] 2015 [cited 2018 Dec 10];13:307-312.

7. Gupta A, Ankola AV, Hebbal M. Dental ergonomics to combat musculoskeletal disorders: a review. International Journal of Occupational Safety and Ergonomics. 2013;19(4):561-571.

8. Jabbar TAA. Musculoskeletal disorders among dentist in Saudi Arabia. Pakistan Oral and Dental Journal, 2008;28(1):135-144.

9. Bhagwat S, Hegde S, Mandke L. Prevalence of Musculoskeletal Disorders among Indian Dentists: A Pilot Survey with Assessment by Rapid Entire Body Assessment. World Journal of Dentistry 2015;6(1):39-44.

10. Karibasappa GN, Anandan S, Rajeshwari K. Dentists' Knowledge, Attitude and Behavior towards the Dental Ergonomics. J Dent Med Sci. 2014;13:86-89.

11. Tareen SUK, Khattak Y, Rehman S. Ergonomics related disorder among dentists in Peshawar- A questionnaire Survey. JKCD 2013;3(2):24-29.

12. Madaan V, Chaudhari A. Prevalence and risk factor associated with musculoskeletal pain among students of MGM Dental College: a cross-sectional survey. J Contemp Dent Pract. 2012;2(2):22-27

13. Szymanska J. Dentist's hand symptoms and high-frequency vibration. Ann Agric Environ Med.2001;8:7-10.

14. Hamann C, WERNER RA, Franzblau A, Rodgers PA, Siew C, Gruninger S. Prevalence of carpal tunnel syndrome and median mononeuropathy among dentists. The Journal of the American Dental Association. 2001 Feb 1;132(2):163-170.

15. Dong H, Loomer P, Villanueva A, Rempel D. Pinch forces and instrument tip forces during periodontal scaling. Journal of periodontology. 2007 Jan;78(1):97-103.

16. Roquelaure Y, Mechali S, Dano C, Fanello S, Benetti F, Bureau D. Occupational and personal risk factors for carpal tunnel syndrome in industrial workers. Scand J Work Environ Health 1997;23(5):364-369.

17. Silverstein BA, Fine LJ, Armstrong TJ. Occupational factors and carpal tunnel syndrome. Am J Ind Med 1987;11(3):343-358.

18. de Carvalho MV, Soriano EP, de Franca Caldas A Jr, Campello RI, de Miranda HF, Cavalcanti FI. Work-related musculoskeletal disorders among Brazilian dental students. J Dent Educ 2009; 73:624-630

19. Diaz-Caballero AJ, Gómez-Palencia IP, Díaz-Cárdenas S. Ergonomic factors that cause the presence of pain muscle in students of dentistry. Med Oral Patol Oral Cir Bucal. 2010 Nov 1;15(6):e906.

20. Tamrooiy FR, Javar MA, Salimi S, Mohammadpour H, Avakh A, Faizollahi S. A survey on Prevalence of Musculoskeletal Disorders in Dentists of Tehran and their posture assessment by RULA method. International Research Journal of Applied and basic Sciences 2015;9(5):666-671. 